\title{
Juvenile Aggressive Ossifying Fibroma in a 6-Months Old: A Case Report
}

\author{
Mmathabo Gloria Sekhoto*, Risimati Ephraim Rikhotso \\ Department of Maxillofacial and Oral Surgery, University of the Witwatersrand, Johannesburg, South Africa \\ Email: ^drsekhoto@gmail.com
}

How to cite this paper: Sekhoto, M.G. and Rikhotso, R.E. (2017) Juvenile Aggressive Ossifying Fibroma in a 6-Months Old: A Case Report. Open Journal of Stomatology, 7, 481-487.

https://doi.org/10.4236/ojst.2017.711044

Received: September 29, 2017

Accepted: November 7, 2017

Published: November 10, 2017

Copyright $\odot 2017$ by authors and Scientific Research Publishing Inc. This work is licensed under the Creative Commons Attribution International License (CC BY 4.0).

http://creativecommons.org/licenses/by/4.0/

\section{(c) (i) Open Access}

\begin{abstract}
Juvenile Aggressive Ossifying Fibroma (JAOF) is a benign but locally aggressive fibro-osseous lesion. It is a rapidly growing non-odontogenic neoplasm of the jaws, generally occurring in children and young adults. It is often confused with malignant condition because of its clinical behaviour. Long term follow-up is necessary, considering the high recurrence nature of this tumour. The reconstruction of affected patients, particularly the younger, is often challenging since it has to be done in stages, to keep up with the developing face. We report a case of maxillary JAOF in a 6-month-old female who was referred to our department. Histopathological examination of a resected specimen revealed a trabecular type of JAOF. The patient was followed up for a period of 2 years.
\end{abstract}

\section{Keywords}

Juvenile Aggressive Ossifying Fibroma, Juvenile Ossifying Fibroma, Fibro-Osseous Lesions

\section{Introduction}

Juvenile Aggressive Ossifying Fibroma (JAOF) is a relatively rare, asymptomatic, actively growing, benign non-odontogenic neoplasm of the jaws. It generally occurs in children and young adults under 15 years of age in more than $80 \%$ of cases [1] [2] [3]. It is distinguishable from conventional ossifying fibroma on the basis of patient's age, rapid growth and high recurrence rate [2] [3]. Although it is often confused with malignant conditions because of its clinical behaviour [4] [5], no malignant transformation has however been reported [3] [6].

JAOF has two histopathologic variants, namely, Psammomatoid and Trabecular. Psammomatoid JAOF is more commonly reported than the trabecular 
type and affects patients from a wide age range ( 3 months to 72 years). It usually occurs in the paranasal sinuses, periorbital and craniofacial skeleton [1] [2] [3] [7].

Trabecular JAOF occurs in children between 2 to 33 years of age, with average age of 12 years. It affects the jaws and more frequently, the maxilla [2].

Management of these conditions tends to be difficult due to the aggressive nature of these conditions, as well as the high recurrence rate, particularly on very young patients. Surgical resection rather than conservative curettage is therefore, the preferred treatment of choice [2]. There are challenges in restoration of anatomical form especially in the very young patient.

\section{Case Report}

A 6-month-old female patient presented with a 2 months history of a rapidly growing swelling on her left cheek. She was referred from an ENT specialist, with an incisional biopsy results suggestive of a fibro-osseous lesion (fibrous dysplasia or juvenile ossifying fibroma).

On extraoral examination (Figure 1) a diffuse, painless, rubbery firm swelling was noted on the left cheek. Obliteration of the left alar facial groove and flaring of the alar were noted. Her left eye appeared pseudoptotic and proptotic but was superiorly displaced with resultant distension of the left upper eyelid. Intraorally, she presented with a firm swelling in the left maxilla, which obliterated the buccal vestibule. The overlying mucosa was normal.

CT Scans revealed a well-circumscribed heterogenous lesion in the left maxillary sinus, with displacement of the orbital floor (Figure 2).

The tumour was resected in toto using the Weber Fergusson approach, under general anaesthesia. A curved $1.5 \mathrm{~mm}$ titanium miniplate was used to reconstruct the left infraorbital rim. A resorbable mesh (Lactosorb, Zimmer Biomet)

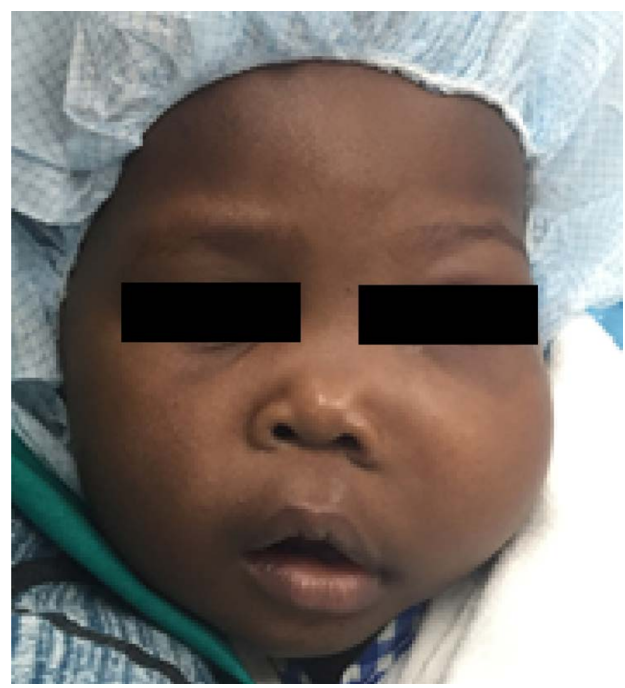

Figure 1. Extraoral examination revealed a diffused swelling on the left cheek. There was left eye proptosis with narrowing of the palpebral fissure. Obliteration of the left nasolabial fold, flaring of the alar were noted. 

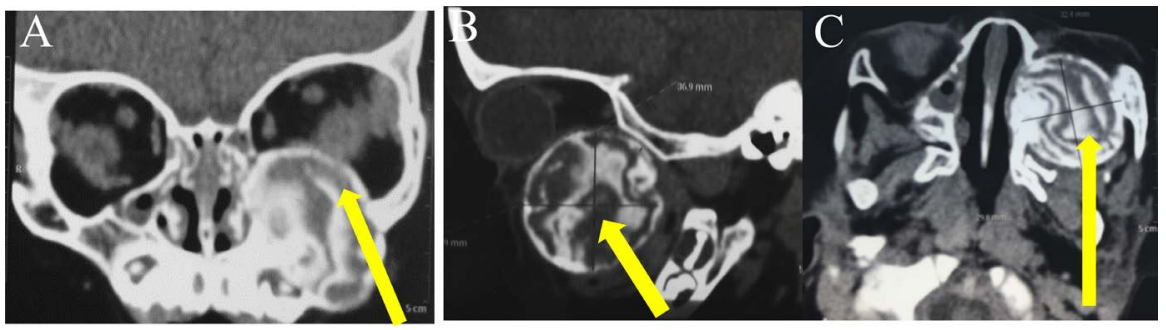

Figure 2. CT scans revealed well-circumscribed, heterogenous lesion (yellow arrows) in the left maxillary sinus, with superior displacement of orbital floor ((A) coronal section; (B) sagittal section; (C) axial section).

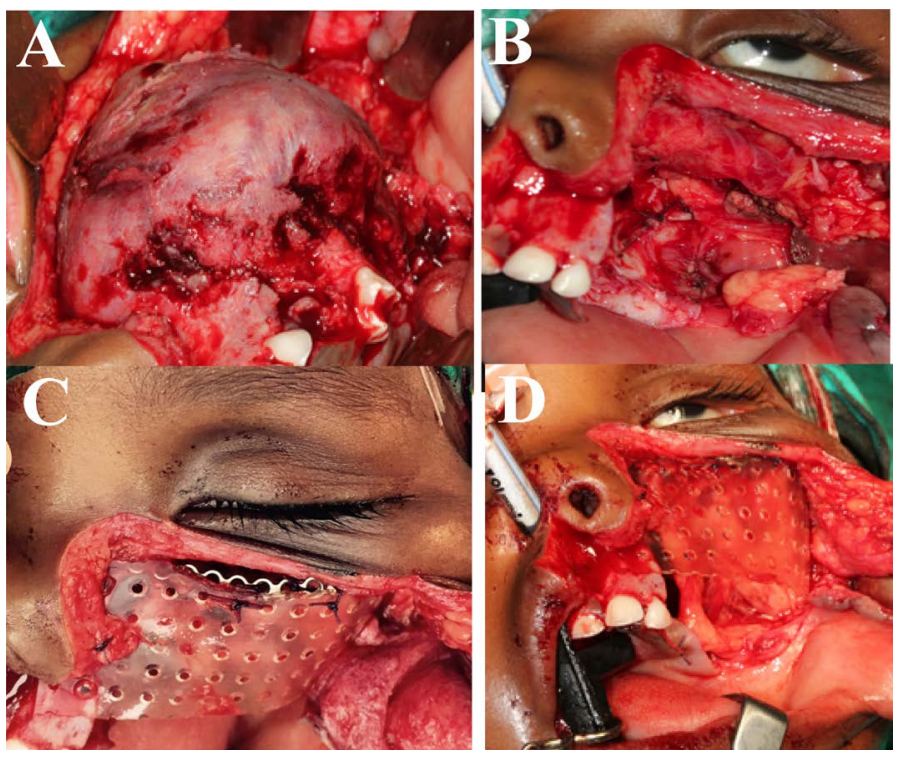

Figure 3. Intra-operative images showing (A) the tumour; (B) the zygomatico-maxillary defect; (C) the titanium plate \& Lactosorb; and (D) the reconstruction with buccal fat pad.

was secured onto the plate to reconstruct the orbital floor and the zygomaticomaxillary defect. The defect was filled with buccal fat pad (Figure 3 ).

Histopathologic examination of the resected specimen confirmed a diagnosis of a benign fibro-osseous lesion most consistent with a juvenile ossifying fibroma (Figure 4).

It revealed fibrous connective tissue that exhibited areas that were loose and other zones that were cellular. There was evidence of occasional myxomatous foci with associated areas of pseudocystic degeneration. Areas of haemorrhage and numerous clusters of multinucleated giant cells were present.

The mineralised component showed a trabecular pattern with irregular strands of highly cellular osteoid encasing plump and irregular osteocytes. The bone trabeculae were lined by plump osteoblasts with areas of multinucleated osteoclasts.

Our patient was followed up at 12 months (Figure 5(A)) and 24 months (Figure 5(B)) post-surgery, and she had healed uneventfully. Post-operative CTs at 24 months did not reveal any recurrence (Figure 6(A) and Figure 6(B)). 


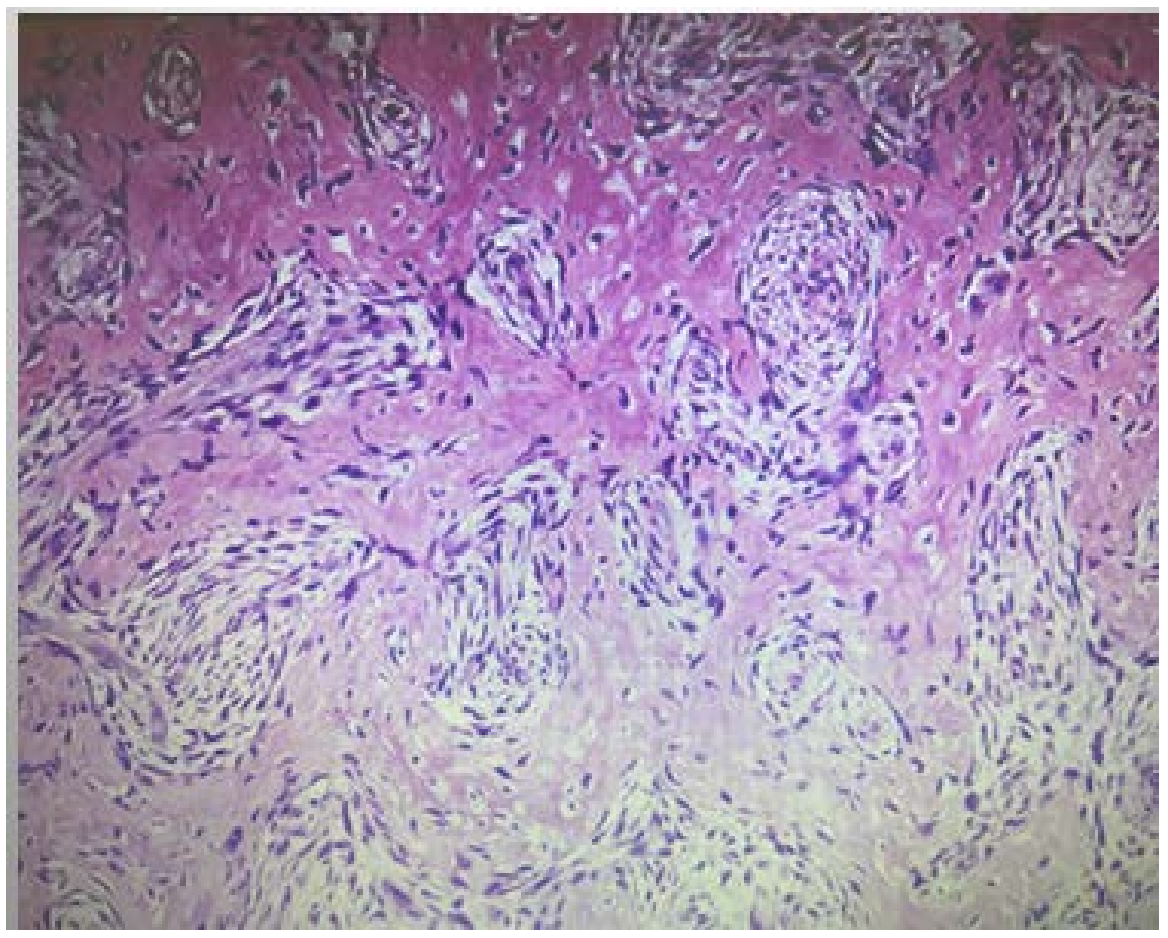

Figure 4. Histology reveals mineralised component showing a trabecular pattern with strands of highly cellular osteoid encasing plump and irregular osteocytes.

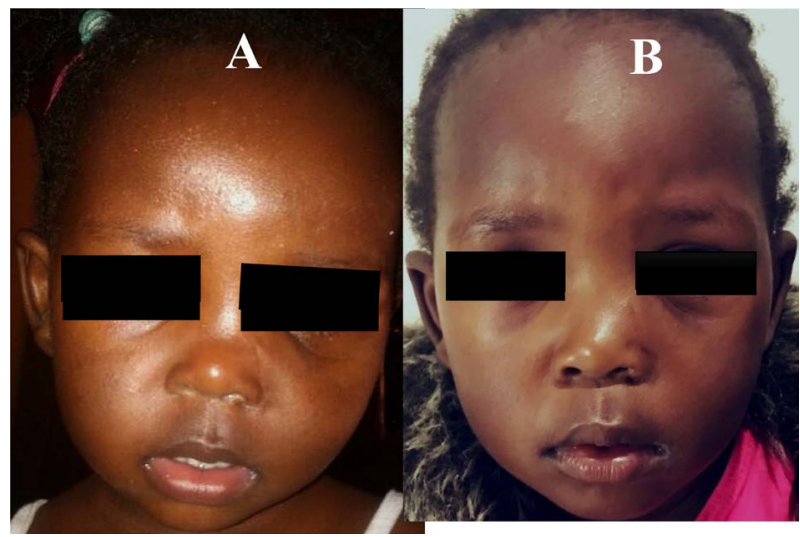

Figure 5. Post-operative: (A) 12 months review; (B) 24 months review.

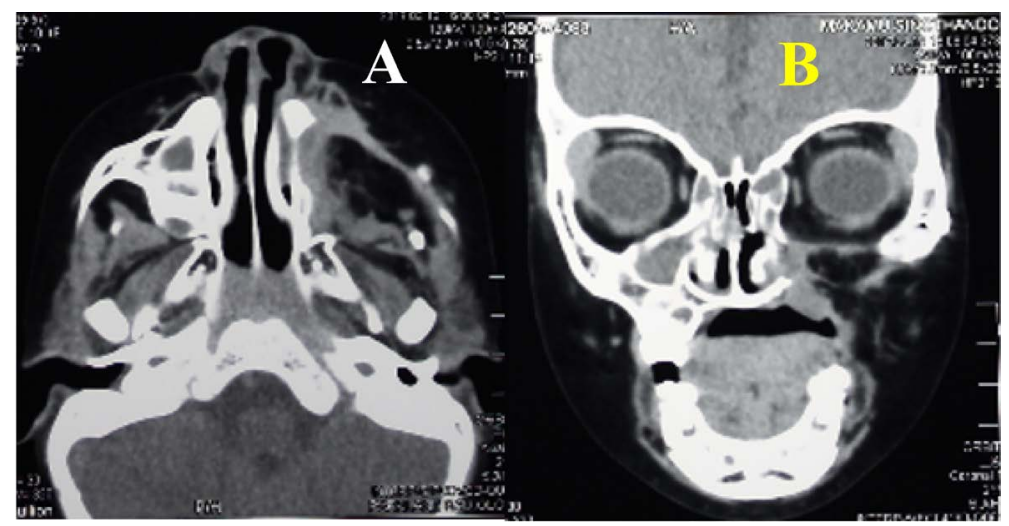

Figure 6. Post-operative CT scan views: (A) axial section and (B) coronal section. 


\section{Discussion}

Ossifying fibroma is an uncommon benign fibro-osseous lesion, which compromises $2 \%$ of oral tumours in children [8] [9] [10]. Fibro-osseous lesions are characterised by replacement of bone by formation of woven, lamellar bone with dense amorphous mineralisation [11]. The calcified tissue resembles bone, cementum or both. The lesions are the result of maturation by cellular fibrous tissue, formed by the replaced bone [12]. OF lesions are classified as conventional OF and juvenile OF [13]. Conventional OF is mainly seen in adults. JOF (also known as Juvenile aggressive OF or Juvenile Active OF) occurs mainly in children or adolescents. $85 \%$ of JAOF lesions originate in the facial bones (maxilla being more common than mandible), amongst which $90 \%$ arise within paranasal sinuses. $12 \%$ occur in the calvarial bones and $4 \%$ are extra-cranial [14]. Depending on the bone involved, symptoms can vary from proptosis, exophthalmos, nasal congestion and sinusitis.

The aetiology of JAOF is poorly understood. It is thought to arise from mesenchymal cell differentiation of periodontal ligaments-which is a precursor to cementum, fibrous tissue and osteoid [12].

Differential diagnosis for JAOF includes fibrous dysplasia, aneurysmal bone cyst, osteosarcoma, osteoblastoma and cemento-osseous dysplasia. Its propensity to be monostotic, having rapid growth and radiologically having well-demarcated margins, differentiates it from fibrous dysplasia [15].

As demonstrated in this case, JAOF is clinically characterized by painless, rapidly growing swelling, with obvious facial asymmetry [1] [2] [3] [6] [7]. Paraesthesia is rarely reported [3] [6]. The orbito-nasal tumours may cause nasal obstruction, sinusitis, proptosis, diplopia and blindness [3] [4]. Our patient presented with nasal obstruction and superior displacement of the left orbital floor. Those tumours that have penetrated the cranial cavity may result in encephalitis and meningitis. Gnathic lesion can cause tooth displacement, root resorption, and failure of a tooth to develop [3] [4] [7].

Radiographically, JAOF appears as a well-circumscribed radiolucent, or mixed radiolucent and radiopaque lesion. Opacification of the sinus is usually seen in cases involving the sinuses [2] [3] [5] [7]. Our patient had complete opacification of the left maxillary sinus.

Psammomatoid JAOF is more aggressive, more frequent and has a high tendency to recur. In our patient, the histopathologic examination of the resected specimen comprised of mineralised component which showed a trabecular pattern with irregular strands of highly cellular osteoid encasing plump and irregular osteocytes [1] [2] [3]. Our patient was much younger than the age range reported for the trabecular type.

Management JAOF tends to be difficult due to its aggressive nature, as well as the high recurrence rate. Surgical resection rather than conservative curettage is the preferred treatment [2]. Surgical treatment, however, results in major hard and soft tissue defects which impact not only cosmesis and function but cra- 
niofacial development as well. Reconstruction of these post-tumour ablative defects poses a big challenge, particularly in children.

Both the resorbable mesh and buccal fat pad have allowed interim reconstruction of our patient, but it is likely that the patient will require multiphasic and multidisciplinary reconstruction at a later stage.

Recurrence rates vary from $30 \%$ to $58 \%$ in the literature, with recurrences seen anywhere between 6 months and 7 years [11]. Hence a minimum 5 year follow-up is advocated in these patients [16] [17]. Our patient is being followedup regularly, and had no sign of recurrence at the 2 year follow-up.

\section{Conclusion}

JAOF is considered an aggressive benign tumour. It is relatively rare and often affects young patients. Management of JAOF in children poses a serious challenge, because the tumour is rapidly growing and often extends deep into craniomaxillary spaces at the time of diagnosis. Although the tumour was excised in its entirety, the prognosis of JAOF is uncertain and long term follow up is mandatory. To the best of our knowledge this is the first reported case of JAOF in a 6 month child.

\section{Conflict of Interest}

None.

\section{Compliance with Ethical Standards}

Informed consent was obtained from the parents.

\section{References}

[1] Kramer, I.R., Pindborg, J.J. and Shear, M. (1992) The World Health Organisation Histological Typing of Odontogenic Tumours. A Commentary on the 2nd Edition. Cancer, 70, 2988-2994. https://doi.org/10.1002/1097-0142(19921215)70:12<2988::AID-CNCR2820701242> 3.0.CO;2-V

[2] El-Mofty, S. (2002) Psammomatoid and Trabecular Juvenile Ossifying Fibroma of the Craniofacial Skeleton: Two Distinct Clinicopathologic Entities. Oral Surgery, Oral Medicine, Oral Pathology, Oral Radiology and Endodontics, 93, 296-304. https://doi.org/10.1067/moe.2002.121545

[3] Neville, B.W., Damm, D.D., Allen, C.M. and Chi, A.C. (2016) Oral \& Maxillofacial Pathology. 4th Edition, WB Saunders, Elsevier, Missouri, 604-605.

[4] Rinaggio, J., Land, M. and Cleveland, D.B. (2003) Juvenile Ossifying Fibroma of the Mandible. Journal of Pediatric Surgery, 38, 648-650.

[5] Breheret, R., Jeufroy, C., Cassagnau, E. and Malard, O. (2011) Juvenile Ossifying Fibroma of the Maxilla. European Annals Otorhinolaryngology, Head Neck Diseases, 128, 317-320. https://doi.org/10.1016/j.anorl.2011.02.007

[6] Guruprasad, Y. and Giraddi, G. (2009) Juvenile Ossifying Fibroma of Maxilla. Journal of Maxillofacial and Oral Surgery, 1, 96-98.

[7] Kubbi, J.R., Kumar, N., Reddy, V. and Ramlal, G. (2011) Juvenile Ossifying Fibro- 
ma. Journal of Dental Sciences and Research, 2, 64-66.

[8] Han, J., Hu, L., Zhang, C., Yang, X., et al. (2016) Juvenile Ossifying Fibroma of the Jaws: Retrospective Study of 15 Cases. International Journal of Oral and Maxillofacial Surgery, 45, 368-376. https://doi.org/10.1016/j.ijom.2015.12.004

[9] Matsuzaka, K., Shimono, M., Uchiyama, T., Noma, H. and Inoue, T. (2002) Lesions Related to the Formation of Bone, Cartilage or Cementum Arising in the Oral Area: A Statistical Study and Review of the Literature. The Bulletin of Tokyo Dental College, 43, 173-180. https://doi.org/10.2209/tdcpublication.43.173

[10] Maaita, J.K. (2000) Oral Tumours in Children: A Review. Journal of Clinical Pediatric Dentistry, 24, 133-135.

[11] Vamanshankar, H., Karunakaran, V., Parida, P., Hegde, J., Ganesan, S. and Alexander, A. (2017) Giant Trabecular Type Juvenile Ossifying Fibroma of the Maxilla-A Case Report. Revista Española de Cirugía Oral y Maxilofacial, 39, 229-238. https://doi.org/10.1016/j.maxilo.2016.10.003

[12] Cawson, R.A. and Odell, E.W. (2008) Cawson's Essentials of Oral Pathology and Oral Medicine. 8th Edition, Churchill Livingstone Elsevier, London, 146-183.

[13] Barnes, L., Eveson, J.W., Reichart, P. and Sidransky, D. (2005) World Health Organisation Classification of Tumours. Pathology and Genetics-Head and Neck Tumours. IARC Press, Lyon.

[14] Johnson, L.C., Yousefi, M., Vinh, T.N., Heffner, D.K., Hyams, V.J. and Hartman, K.S. (1991) Juveniel Aggressive Ossifying Fibroma. Its Nature, Dynamics and Origin. Acta Oto-Laryngologica Supplementum, 488, 1-40.

[15] Osunde, O.D., Lyogun, C.A. and Adebola, R.A. (2013) Juvenile Aggressive Ossifying Fibroma of the Maxilla: A Case Report and Review of the Literature. Annals of Medical and Health Sciences Research, 3, 288-290.

[16] Makek, M.S. (1987) So-Called "Fibro-Osseous Lesions" of Tumour Origin. Biology Confronts Terminology. Journal of Cranio-Maxillo-Facial Surgery, 15, 154-167. https://doi.org/10.1016/S1010-5182(87)80040-9

[17] Eversole, L.R., Leider, A.S. and Nelson, K. (1985) Ossifying Fibroma: A Clinicopathologic Study of Sixty Four Cases. Oral Surgery, Oral Medicine, Oral Pathology, Oral Radiology, 60, 505-511. https://doi.org/10.1016/0030-4220(85)90239-7 